\title{
Antiplatelet therapy in patients receiving aortic bioprostheses: A report of clinical and instrumental safety
}

\author{
Francesca di Marco, MD, PhD, ${ }^{a}$ Silvia Grendene, MD, ${ }^{a}$ Giuseppe Feltrin, MD, ${ }^{\text {a }}$ Dino Meneghetti, MD, and \\ Gino Gerosa, MD ${ }^{\mathrm{a}}$
}

From the Department of Cardiologic, Thoracic and Vascular Sciences, Division of Cardiac Surgery and Neurology Division, ${ }^{\mathrm{b}}$ Padua University Medical School, Padova, Italy.

Received for publication July 25, 2006; revisions received Oct 17, 2006; accepted for publication Dec 6, 2006

Address for reprints: Dr Gino Gerosa, Department of Cardiologic, Thoracic and Vascular Sciences, Division of Cardiac surgery, Padua University Medical School, Via Giustiniani 2, 35100 Padova, Italy (Email: gino.gerosa@unipd.it).

J Thorac Cardiovasc Surg 2007;133:1597-603 $0022-5223 / \$ 32.00$

Copyright (c) 2007 by The American Association for Thoracic Surgery

doi:10.1016/j.jtcvs.2006.12.060
Objective: The main advantage of bioprostheses, avoidance of anticoagulant therapy, is compromised during the early postoperative period; in fact, warfarin is often administered during the first 3 postoperative months.

Methods: We analyzed 250 patients undergoing tissue aortic valve replacement between January 2002 and December 2005. The patients received either aspirin (group 1) or oral anticoagulation (group 2) during the first 3 months. In a subgroup of these patients, we investigated the possible presence of clinically silent microembolization by means of transcranial Doppler for microembolic signal detection.

Results: Thirty-day mortality was $0 \%$. No major neurologic events occurred. Two episodes of bleeding were observed in both groups. Follow-up time was $24 \pm 14$ months. Overall late mortality rate was $0.8 \%$ in group 1 versus $12 \%$ (mainly cancer related) in group 2. In group 2, 2 deaths were due to major ischemic neurologic events; overall, 3 major neurologic episodes occurred (international normalized ratio was within therapeutic range). There were no neurologic events in group 1 ( $P$ $=.12$ ). Stroke-free survival did not reach statistical significance between the 2 groups. Transcranial Doppler was performed after a mean interval of $55 \pm 19$ days, with no detection of microembolic signals in patients receiving either aspirin or warfarin. There were no episodes of bleeding or neurologic events.

Conclusions: Aspirin therapy appears to be the appropriate response to both cardiac surgeons' and patients' needs in the early postoperative course after aortic valve replacement with tissue valves, demonstrating adequate antithromboembolic efficacy with no added risk for bleeding as well as ease of administration.

I $\mathrm{n}$ the first 3 postoperative months after biologic valve replacement, patients are recognized to be at higher risk for thromboembolic events, therefore requiring antithrombotic prophylaxis. ${ }^{1}$ According to the American College of Cardiology (ACC)/American Heart Association (AHA) guidelines, antithrombotic therapy should be administered during this time frame until the exposed components of the bioprosthesis are fully endothelialized. In the previous edition (1998), warfarin was recommended during the first 3 postoperative months after biologic valve replacement (class I). ${ }^{2}$ In the most recent edition (2006), aspirin is indicated at 75 to 100 mg per day after biologic valve replacement in patients with no risk factors (class I, level of evidence C), and warfarin therapy (international normalized ratio [INR] 2.5-3.5) is suggested as a class IIa recommendation (level C). ${ }^{3}$

Since the 1980s, cardiac surgeons have been practicing policies different from warfarin, mainly based on antiplatelet agents, which offer the advantages of an easier administration modality as well as a reduced risk for postoperative bleeding when compared with warfarin. However, we believe that evidence-based clinical and instrumental data are mandatory to provide additional information. With the aim to evaluate the clinical impact of the antithrombotic therapy in patients receiving 


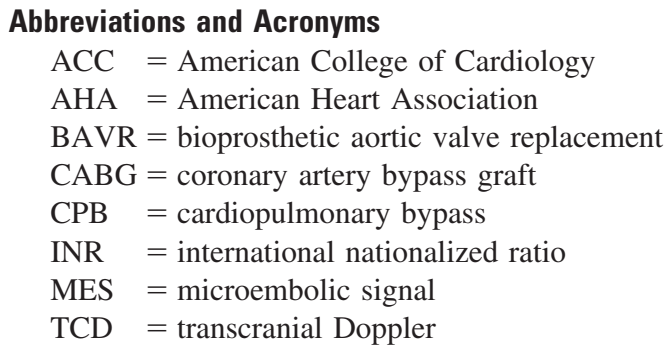

aortic bioprostheses and to provide instrumental data supporting either strategy, we analyzed 250 consecutive patients undergoing tissue aortic valve replacement at our institution (single-center study) between January 2002 and December 2005; the patients received either oral anticoagulation or aspirin as antithrombotic prophylaxis during the first 3 postoperative months. Additionally, in a subgroup of these patients, we investigated the possible presence of clinically silent microembolization by means of transcranial Doppler (TCD) for microembolic signal (MES) detection. Therefore, this study provides both clinical and instrumental data supporting the evidence that antiplatelet therapy alone is safe and effective for patients receiving aortic bioprostheses.

\section{Materials and Methods \\ Patients}

The study population consisted of 250 patients divided into 2 arms. The first arm included 200 consecutive patients (103 men, 97 women; mean age $76 \pm 4$ years) who underwent bioprosthetic aortic valve replacement (BAVR) at our institution between January 2002 and September 2005. Patients were divided into 2 groups according to the postoperative antithrombotic regimen. According to the operating surgeon's preference, patients were treated either with warfarin (target INR 2-3; 100 patients) or aspirin $(100 \mathrm{mg} / \mathrm{d} ; 100$ patients). All patients were prospectively entered into the study. The patient data were prospectively collected at the time of the operation, and patients were prospectively followed by both ambulatory clinical evaluations and phone interviews at repeated intervals. The second arm included 50 consecutive patients ( 25 men, 25 women; mean age $75 \pm 5$ years) operated on between April and October 2005. These 50 patients, who received an aortic valve bioprosthesis, were randomly assigned to receive either antiplatelet therapy (group APMES: 25 patients) or oral anticoagulation (group ACMES: 25 patients) during the first 3 postoperative months. The patients were prospectively entered into the study and preoperative, operative, and postoperative data were prospectively collected. Follow-up ambulatory clinical evaluations were planned. These patients were also monitored by TCD for MES detection before discharge and within the first 3 postoperative months.

According to the exclusion criteria, all patients affected by comorbidities requiring chronic antithrombotic therapy and who were receiving preoperative warfarin were excluded from the
TABLE 1. Demographic data

\begin{tabular}{|c|c|c|c|}
\hline & $\begin{array}{c}\text { Group 1, } \\
\text { n }=125 \\
(\%)\end{array}$ & $\begin{array}{c}\text { Group 2, } \\
\text { n }=125 \\
(\%)\end{array}$ & $\boldsymbol{P}$ \\
\hline Sex & & & .75 \\
\hline Male & $67(53)$ & $65(52)$ & \\
\hline Female & $58(46)$ & $60(48)$ & \\
\hline Age (y) & $75 \pm 6$ & $75 \pm 5$ & .5 \\
\hline Hypertension & $65(52)$ & $57(46)$ & .28 \\
\hline Diabetes & $27(22)$ & $28(22)$ & .97 \\
\hline Dyslipidemia & $37(30)$ & $29(23)$ & .21 \\
\hline Peripheral artery disease & $26(21)$ & $17(14)$ & .1 \\
\hline Carotid artery stenosis (>50\%) & $10(8)$ & $17(14)$ & .15 \\
\hline Coronary artery disease & $33(26)$ & $33(26)$ & \\
\hline $\begin{array}{l}\text { Prior cerebrovascular } \\
\text { accidents }\end{array}$ & $8(6)$ & $14(11)$ & .18 \\
\hline $\begin{array}{l}\text { Atrial fibrillation (previous atrial } \\
\text { fibrillation, now sinus } \\
\text { rhythm) }\end{array}$ & $7(6)$ & $10(8)$ & .45 \\
\hline \multirow[t]{2}{*}{ Redo } & $3(2)$ & $6(5)$ & .31 \\
\hline & $\begin{array}{c}\text { APMES, } \\
\text { n }=25 \\
(\%)\end{array}$ & $\begin{array}{c}\text { ACMES, } \\
\text { n }=25 \\
(\%)\end{array}$ & $\boldsymbol{P}$ \\
\hline Sex & & & .32 \\
\hline Male & $16(64)$ & $13(52)$ & \\
\hline Female & $9(36)$ & $12(48)$ & \\
\hline Age (y) & $75 \pm 5$ & $75 \pm 5$ & .86 \\
\hline Smoking history & $8(32)$ & $12(48)$ & .32 \\
\hline Hypertension & $20(80)$ & $23(92)$ & .24 \\
\hline Diabetes & $4(16)$ & $8(32)$ & .27 \\
\hline Dyslipidemia & $10(40)$ & $19(76)$ & .01 \\
\hline Peripheral artery disease & $3(12)$ & $3(12)$ & .67 \\
\hline Carotid artery stenosis ( $\leq 50 \%)$ & $7(28)$ & $7(28)$ & .9 \\
\hline Carotid artery stenosis $(>50 \%)$ & $4(16)$ & $2(8)$ & .17 \\
\hline Prior cerebrovascular event & $4(16)$ & $3(12)$ & .73 \\
\hline Atrial fibrillation & $2(8)$ & $7(28)$ & .15 \\
\hline Redo & $1(4)$ & 1 (4) & .98 \\
\hline $\begin{array}{l}\text { Prior acute myocardial } \\
\text { infarction }\end{array}$ & 0 & 2 (8) & .14 \\
\hline \multicolumn{4}{|l|}{ Coronary artery disease } \\
\hline$>75 \%$ & $4(16)$ & $5(20)$ & .66 \\
\hline$<75 \%$ & 2 (8) & $6(24)$ & .11 \\
\hline \multicolumn{4}{|l|}{ Aortic valve disease } \\
\hline Aortic stenosis & $19(76)$ & $20(80)$ & .57 \\
\hline Aortic insufficiency & $3(12)$ & $1(4)$ & .32 \\
\hline Mixed disease & $3(12)$ & $4(16)$ & .64 \\
\hline LVEF (\%) & $56 \pm 11$ & $57 \pm 12$ & .85 \\
\hline LVEDV $\left(\mathrm{mL} / \mathrm{m}^{2}\right)$ & $73 \pm 24$ & $61 \pm 12$ & .04 \\
\hline
\end{tabular}

$L V E F$, Left ventricle ejection fraction; LVEDV, left ventricle end-diastolic volume.

study. Also, patients receiving concomitant mitral/tricuspid valve replacement were excluded from the study. Demographic data of the overall patient population as well as specific data of patients investigated for MES detection are listed in Table 1. 
The outcome variables were defined according to the guidelines for reporting morbidity and mortalitity after cardiac valvular operations. $^{4}$

\section{Surgical Technique}

Operations were performed through median sternotomy, by cardiopulmonary bypass (CPB), with moderate hypothermia, and with aortic crossclamp. Myocardial ischemic arrest was achieved with cold blood cardioplegic solution, either antegrade and retrograde, administered at 20-minute intervals. The aortic bioprosthesis was implanted through a transaortic approach, using multiple interrupted noneverted 2-0 Ticron (Ethicon, Somerville, NJ) sutures, reinforced with Teflon (Boston Scientific, Natick, Mass) pledgets.

\section{Antithrombotic Therapy}

Low-molecular-weight heparin was routinely administered starting from the first postoperative day in the absence of significant blood loss from drainage tubes. Oral antithrombotic prophylaxis was started on the second postoperative day. One hundred twenty-five patients received aspirin (100 mg/d; group 1), and 125 patients were treated with warfarin (group 2), maintaining a target INR of 2 to 3 (group AC). Subcutaneous heparin was discontinued once patients were fully mobilized (group 1) or target INR was reached (group 2).

\section{Patient Follow-up}

All patients were prospectively followed. The patients were periodically visited at our outpatient clinic plus contacted by phone for clinical interviews at repeated intervals. The anticoagulant/antiaggregant therapy assumed was ascertained, and INR was monitored in all anticoagulated patients. New York Heart Association class was adopted to score patients' clinical status. Additionally, in 50 patients (second study arm), 30-minute TCD by a multifrequency Doppler instrumentation (EmboDop, DWL, Singen, Germany) through transtemporal window was performed for MES detection. All TCDs were carried out and analyzed by a single neurologist within the first 3 postoperative months.

\section{Statistical Analysis}

Differences among the patients of the 2 groups were tested with Student $t$ test for independent samples for normally distributed variables, and $\chi^{2}$ test was used to evaluate nominal qualitative variables. Analysis of variance for repeated measures was used to test the significance of side and group. Statistics were performed by means of the STATISTICA 6 package (Statsoft Inc, 1984-2004).

\section{Results}

\section{Operative Results}

The overall operative data of the 250 patients are reported in Table 2, including specific data regarding the 50 patients who underwent MES investigation. All patients received a stented bioprosthesis: 128 Carpentier-Edwards Perimount (Edwards Lifesciences, Irvine, Calif) pericardial valves (50 in group 1 vs 78 in group 2) and 122 St Jude Biocor/Epic (St Jude Medical, Inc, St Paul, Minn) porcine bioprostheses (75
TABLE 2. Operative data

\begin{tabular}{|c|c|c|c|}
\hline & $\begin{array}{c}\text { Group } 1 \\
\mathrm{n}=125 \\
(\%)\end{array}$ & $\begin{array}{c}\text { Group } 2 \\
\mathrm{n}=125 \\
(\%)\end{array}$ & $\boldsymbol{P}$ \\
\hline Isolated BAVR & $73(58)$ & $82(66)$ & \\
\hline BAVR + other surgical procedures & $52(42)$ & $43(34)$ & .44 \\
\hline BAVR + CABG & 35 & 34 & \\
\hline $\begin{array}{l}\text { BAVR + ascending aorta } \\
\text { replacement }\end{array}$ & 8 & 4 & \\
\hline BAVR + carotid TEA & 5 & 4 & \\
\hline Other & 4 & 1 & \\
\hline $\begin{array}{l}\text { Aortic bioprosthesis implanted } \\
\text { Carpentier-Edwards } \\
\text { Perimount }\end{array}$ & $50(40)$ & $78(62)$ & \\
\hline \multirow[t]{2}{*}{ Biocor/Epic } & $75(60)$ & $47(38)$ & \\
\hline & $\begin{array}{l}\text { APMES } \\
\mathrm{n}=25 \\
(\%)\end{array}$ & $\begin{array}{c}\text { ACMES } \\
n=25 \\
(\%)\end{array}$ & $P$ \\
\hline Body surface area $\left(\mathrm{m}^{2}\right)$ & $1.8 \pm 0.1$ & $2 \pm 0,2$ & .85 \\
\hline AVR & $12(48)$ & $14(56)$ & \\
\hline AVR + associated procedures & $13(52)$ & $11(44)$ & .57 \\
\hline AVR + coronary artery bypass grafting & 6 & 6 & \\
\hline AVR + ascending aorta replacement & 3 & 2 & \\
\hline $\begin{aligned} \text { AVR } & + \text { ascending aorta replacement } \\
& + \text { carotid TEA }\end{aligned}$ & 1 & 0 & \\
\hline Others & 3 & 3 & \\
\hline Aortic crossclamp time (min) & $103 \pm 34$ & $101 \pm 30$ & .72 \\
\hline Cardiopulmonary bypass (min) & $144 \pm 60$ & $134 \pm 36$ & .72 \\
\hline \multicolumn{4}{|l|}{ Aortic bioprosthesis implanted } \\
\hline Carpentier Edwards Perimount & $7(28 \%)$ & $10(40 \%)$ & .37 \\
\hline St Jude Biocor/Epic & $18(72 \%)$ & $15(60 \%)$ & .37 \\
\hline
\end{tabular}

BAVR, Bioprosthetic aortic valve replacement; $C A B G$, coronary artery bypass graft; TEA, thromboendarterectomy; $A V R$, aortic valve replacement.

in group 1 vs 47 in group 2). Associated procedures were performed in $34 \%$ of group 1 patients versus $42 \%$ of group 2 patients $(P=.44)$, mainly consisting of coronary artery bypass graft $(\mathrm{CABG})$. There were no significant differences either in CPB or crossclamp time between the 2 groups.

\section{Postoperative Data}

The postoperative outcome of the overall population is reported in Table 3. In the entire series, 30-day mortality was $0 \%$. No major neurologic events occurred. According to postoperative bleeding, 2 episodes were observed among antiaggregated patients (specifically APMES patients) in 2 patients who underwent concomitant $\mathrm{CABG}$ and required drainage procedures (1 pericardiocentesis and 1 thoracentesis). Two major bleeding episodes also occurred in the anticoagulated cohort.

Specific postoperative data regarding the group of patients investigated with TCD are also shown: mean intensive care unit stay was $1 \pm 1$ days in patients taking 
TABLE 3. Postoperative data

\begin{tabular}{|c|c|c|c|}
\hline & $\begin{array}{c}\text { Group } 1 \\
n=125 \\
(\%)\end{array}$ & $\begin{array}{c}\text { Group } 2 \\
\text { n }=125 \\
(\%)\end{array}$ & $\boldsymbol{P}$ \\
\hline Perioperative $(30-d)$ death & 0 & 0 & \\
\hline $\begin{array}{l}\text { Major neurologic events within } \\
30 \text { postoperative days* }\end{array}$ & 0 & 0 & \\
\hline \multirow{2}{*}{$\begin{array}{l}\text { Major bleeding within } 30 \\
\text { postoperative days* }\end{array}$} & $2(1.6 \%)$ & $2(1.6 \%)$ & \\
\hline & $\begin{array}{l}\text { APMES } \\
n=25\end{array}$ & $\begin{array}{l}\text { ACMES } \\
n=25\end{array}$ & $P$ \\
\hline Intensive care unit stay (d) & $1 \pm 1$ & $1 \pm 1$ & \\
\hline Mechanical ventilation length (h) & $9 \pm 3$ & $10 \pm 5$ & .90 \\
\hline Total postoperative stay (d) & $9 \pm 4$ & $9 \pm 3$ & .96 \\
\hline LVEF, $(\%)$ & $57 \pm 5$ & $55 \pm 7$ & .33 \\
\hline LVEDV, $\left(\mathrm{mL} / \mathrm{m}^{2}\right)$ & $61 \pm 15$ & $63 \pm 17$ & .66 \\
\hline Major neurologic events* & 0 & 0 & \\
\hline Major bleeding* & 2 (8) & 0 & \\
\hline
\end{tabular}

${ }^{*}$ After starting anticoagulation/antiaggregation therapy. LVEF, Left ventricle ejection fraction; LVEDV, left ventricle end-diastolic volume.

aspirin versus $1 \pm 1$ days in anticoagulated patients; mean length of mechanical ventilation $(9 \pm 3$ hours in group APMES vs $10 \pm 5$ hours in ACMES; $P=.9$ ) was not different between the 2 groups, as well as total hospitalization time $(9 \pm 4$ days in group APMES vs $7 \pm$ 7 days in group ACMES; $P=.6$ ). Echocardiographic data regarding postoperative left ventricular volume and function were superimposable.

\section{Follow-up Data}

Follow-up was $100 \%$ complete. Follow-up time was $24 \pm$ 14 months (median time 20 months; range 2-47 months). Overall late mortality rate was $0.8 \%$ ( 1 of 125 patients, cancer-related death) among patients treated with aspirin versus $12 \%$ (15 of 125 patients, mainly cancer-related deaths $)(P=.0003)$ in anticoagulated patients. Among anticoagulated patients, 2 deaths were due to major ischemic neurologic events; overall, 3 major neurologic episodes occurred (INR was within therapeutic range). There were no neurologic events in patients taking aspirin $(P=$ .12). There were no late deaths in the warfarin group due to bleeding. Cancer-related deaths were secondary to impoverished global physical conditions. Stroke-free survival did not reach statistical significance between the 2 groups (Figure 1).

According to the instrumental follow-up, TCD evaluation was performed after a mean time interval of $55 \pm 19$ days (median time 51 days, range 10-90 days) after the operation. No MES signals were detected during a 30minute TCD bilateral examination in either APMES or ACMES group. No patient presented with either minor or

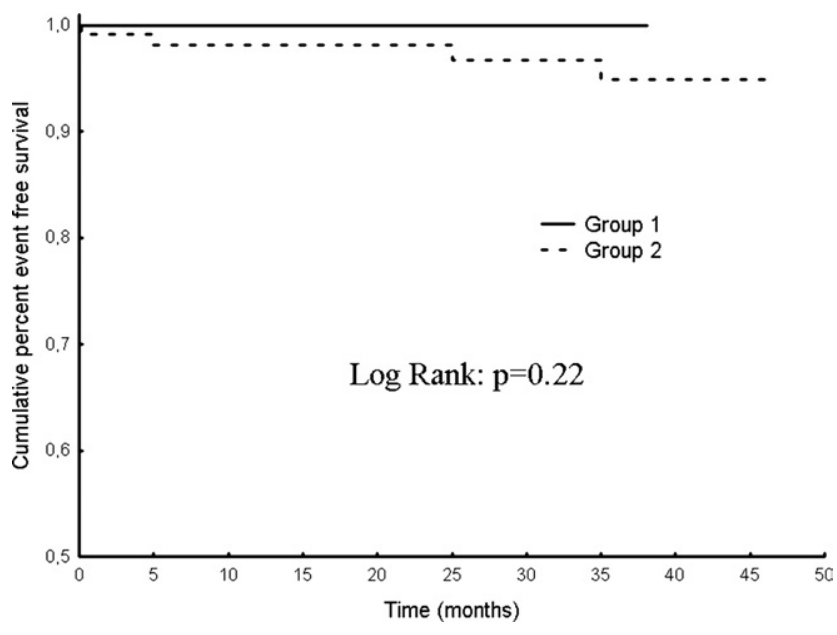

Figure 1. Stroke-free survival.

major neurologic events in either group, and there were no postoperative bleeding episodes.

Overall follow-up data are reported in Table 4 as well as follow up data specifically regarding patients investigated for MES detection (TCD data are also listed).

\section{Discussion}

According to the established guidelines on antithrombotic prophylaxis after valve replacement, oral anticoagulation therapy is required for a limited time after implantation of biologic heart valve prostheses. The ACC/AHA task force recommended warfarin administration with a target INR of 2.5 to 3.5 during the first postoperative months (class I); later, in absence of risk factors for thromboembolism, longterm therapy with aspirin $(80-100 \mathrm{mg} / \mathrm{d})$ is suggested. ${ }^{2}$ In the most recent guidelines' edition (2006), aspirin is indicated at 75 to $100 \mathrm{mg}$ per day after biologic valve replacement in patients with no risk factors (class I, level of evidence C), and warfarin therapy (INR 2.5-3.5) is suggested as a class IIa recommendation (level C). ${ }^{3}$

In the first 3 postoperative months, patients are currently recognized to be at higher risk for thromboembolic events; such risk decreases once the endothelialization process of stent and sutures has been completed. Early oral anticoagulation has been advocated also by the fifth American College of Chest Physicians consensus conference on antithrombotic therapy, according to site of insertion: a grade $\mathrm{C} 1$ recommendation is indicated for mitral prostheses, although the evidence for aortic valves is less compelling (C2). Nevertheless, during the first 3 postoperative months, a target INR of 2.5 was indicated (class A1). ${ }^{5}$ More recently, the seventh American College of Chest Physicians conference recommended either vitamin $\mathrm{K}$ antagonists (grade 2C) or aspirin (grade 1C) as antithrombotic prophy- 
TABLE 4. Follow-up data

\begin{tabular}{|c|c|c|c|}
\hline & $\begin{array}{c}\text { Group } 1 \\
\mathbf{n}=125 \\
(\%)\end{array}$ & $\begin{array}{c}\text { Group } 2 \\
n=125 \\
(\%)\end{array}$ & $\boldsymbol{P}$ \\
\hline Death & $1(0.8 \%)$ & $15(12 \%)$ & .0003 \\
\hline \multicolumn{4}{|l|}{ Cause of death: } \\
\hline Neoplasia & 1 & 5 & \\
\hline Heart failure & 0 & 1 & \\
\hline AMI & 0 & 1 & \\
\hline Endocarditis & 0 & 1 & \\
\hline Cerebral ischemia & 0 & 2 & .12 \\
\hline Other & 0 & 5 & \\
\hline NYHA (III-IV)at follow-up & $2(1.6 \%)$ & $6(4.8 \%)$ & \\
\hline $\begin{array}{l}\text { Major neurologic events after } 30 \\
\text { postoperative days* }\end{array}$ & 0 & $3(2.4 \%)$ & .12 \\
\hline \multirow{2}{*}{$\begin{array}{l}\text { Major bleeding after } 30 \\
\text { postoperative days }\end{array}$} & 0 & 0 & \\
\hline & $\begin{array}{l}\text { APMES } \\
n=25\end{array}$ & $\begin{array}{l}\text { ACMES } \\
n=25\end{array}$ & $P$ \\
\hline Death at follow-up & 0 & 0 & \\
\hline Major neurologic events & 0 & 0 & \\
\hline $\begin{array}{l}\text { Major bleeding events } \\
\text { TCD parameters }\end{array}$ & 0 & 0 & \\
\hline Right medium velocity & $49 \pm 12$ & $64 \pm 18$ & .001 \\
\hline Right pulsation index & $1 \pm 0.2$ & $1 \pm 0.2$ & .66 \\
\hline Right depth & $1 \pm 1$ & $1 \pm 0.2$ & .68 \\
\hline Right MES & 0 & 0 & \\
\hline Left medium velocity & $51 \pm 15$ & $61 \pm 1$ & .05 \\
\hline Left pulsation index & $1 \pm 0.2$ & $1 \pm 0.2$ & .54 \\
\hline Left depth & $55 \pm 2$ & $55 \pm 1$ & .76 \\
\hline Left MES & 0 & 0 & \\
\hline
\end{tabular}

*After starting anticoagulation/antiaggregation therapy. AMI, acute myocardial infarction; NYHA, New York Heart Association; TCD, transcranial Doppler; MES, microembolic signal.

laxis during the first 3 months after aortic bioprosthetic implant. ${ }^{6}$

Currently, the vast majority of patients receiving a bioprosthesis are elderly patients, who frequently present with significant comorbidities and have physiologically reduced multiorgan function due to senescence. These patients are therefore prone to possible anticoagulation-related complications, compared with younger patients. Elderly patients would therefore benefit from complete freedom from anticoagulant therapy beginning in the early postoperative period. Besides, during the first few days, oral anticoagulation requires strict INR monitoring by repeated blood sampling. Later, INR monitoring controls may be deferred, but still warfarin action is jeopardized by drug interactions as well as food interactions. ${ }^{7}$ Furthermore, excessive anticoagulation related to warfarin narrow therapeutic index might be responsible for bleeding events in the postoperative period. Antiplatelet therapy, which does not require either assess- ment of therapeutic plasma levels or progressive dosage adjustment, bears evident advantages in terms of patient compliance and comfort. Above all, it would reduce the risks of postoperative bleeding related to excessive anticoagulation.

Since the 1980s, several reports have proposed alternative policies, mainly based on antiplatelet drugs, which have clearly become a reliable alternative to warfarin for cardiac surgeons. ${ }^{8}$ Unfortunately, most published reports are lacking in a prospective randomized approach, which does not adequately strengthen the data with definite evidence.

Despite the absence of evidence-supporting data, in many centers aspirin has currently replaced warfarin as the postoperative antithrombotic treatment of choice after BAVR, as evidenced by a recent CTSNet on-line report. In fact, this survey clearly outlines that the current practice of CTSNet surgeons, even if mostly aware of guidelines, unexpectedly diverge from them. ${ }^{9}$ This diverging trend, confirmed by the Euro Heart Survey Study, ${ }^{10}$ is a reliable mirror of the current practice in many centers, including our institution, where the policy of aspirin administration after BAVR has been adopted in recent years.

More recent work has prospectively compared the clinical outcome of patients undergoing BAVR and treated with anticoagulant regimens or antiplatelet therapies. Gherli and associates prospectively investigated 249 consecutive patients who received either warfarin or aspirin during the first 3 months after BAVR. No statistically significant differences were reported in terms of cerebral ischemic events or early bleeding. ${ }^{11}$

In a retrospective analysis on 1150 patients undergoing BAVR, there was no advantage in terms of embolic stroke protection in anticoagulated patients (intravenous heparin and warfarin) versus patients assuming either aspirin or no antithrombotic therapy at all. ${ }^{12}$ Aramendi and coworkers conducted a prospective multicenter randomized trial in which 199 patients were randomized to antiaggregation (trifusal) or anticoagulation (acenocumarol) after bioprosthetic implant (aortic, mitral, or mitroaortic) with similar results. ${ }^{13}$

After these encouraging results in terms of neurologic outcome, which seem to support the adoption of antiplatelet therapies, especially aspirin, in the early postoperative period after aortic valve replacement with bioprostheses, we decided to prospectively evaluate our patients undergoing BAVR and to compare clinical outcome in patients who, according to operating surgeon's preference, received either warfarin or aspirin as antithrombotic regimen in the first 3 postoperative months. Operative and postoperative results were comparable. Mean ventilation time and length of postoperative stay were similar, as well as bleeding episodes. There were no neurologic complications. 
Because we are convinced that a negative clinical neurologic evaluation cannot exclude the possibility of a silent microembolization, in a subgroup of 50 patients we decided to strengthen the clinical investigation with instrumental data acquired by TCD examination for MES identification. In fact, in a preliminary study on MES occurrence in prosthetic valve recipients, ${ }^{14}$ we could identify a correspondence between the absence of MES signals in patients treated with aspirin instead of warfarin after BAVR and uneventful clinical outcome ( $0 \%$ of neurologic complications and 0\% MES detection). Moreover, we believe that instrumental-based evidence would be necessary to confirm clinical observation and support cardiac surgeons in adopting alternative therapeutic policies.

TCD has recently been proposed for neurologic monitoring after cardiac surgery. ${ }^{15}$ In fact, MESs have been identified both intraoperatively and postoperatively in patients undergoing cardiac surgery on CPB. ${ }^{16}$ Doppler signals that have been interpreted as microbubbles have been related with postoperative neuropsychologic deficits ${ }^{17}$ and alteration of working memory. ${ }^{18}$ In the early 1990s, Doppler signals were detected in patients with prosthetic valves. ${ }^{19}$ In particular, MESs have been recorded in mechanical valve recipients, and an increased MES frequency has been observed in patients presenting with cerebrovascular events compared with asymptomatic patients. ${ }^{20}$ The apparent lack of correlation between MES count and anticoagulation regimen and level, as evidenced by others, ${ }^{21}$ is compatible with a gaseous nature of MES; high-pressure gradients at mechanical valve closure generate cavitationlike phenomena that would be responsible for the creation of microbubbles from dissolved blood gases. Rarely, MES signals have also been seen in patients with biologic valves, ${ }^{22,23}$ but the pathogenetic mechanism is still the object of debate. In the latter case, the different transvalvular flow pattern, with lesser gradients generating at valve closure, is not compatible with the above-mentioned cavitation phenomena, and a different pathogenesis should be addressed. According to a more reliable hypothesis, the high-intensity echoes identified in bioprosthetic valve recipients would be in favor of particulated microaggregates, such as platelets or fibrin microparticles, whose formation might be due to interaction between blood elements and valve components. ${ }^{22}$

Nevertheless, the reported information in the literature about MES prevalence in biologic valve recipients is sparse; conflicting results on correlation between MES count and prevalence of neurologic adverse events mainly refer to mechanical prostheses, in which a different MES generation mechanism is involved. We believe that in tissue valves, TCD evaluation could contribute to overcome a potential underestimation of sheer clinical evaluation (whereas MES identification probably correlates to the presence of micro- thrombotic aggregates). In fact, microembolization, even continuous, might be silent at clinical neurologic evaluation. TCD might add further useful information to clinics with a noninvasive, contrast-free examination and no need for patient exposure to X-rays. The absence of MES at a transcranial evaluation might strengthen the value of neurologic silence at clinical evaluation. With this aim and to further confirm our previous observations, ${ }^{14,24}$ we performed additional instrumental evaluation in 50 patients (25 patients receiving aspirin and 25 patients receiving warfarin), and we did not observe any MES signals in either group.

The clinical and instrumental results of this study confirmed aspirin therapy to be as effective as warfarin in protecting patients with biologic aortic valves from thromboembolic episodes in the early postoperative period. In fact, no neurologic events occurred during the postoperative course, and no signal of microembolization was evident at the TCD evaluation.

Aspirin administration was also associated with optimal patient compliance for the ease of administration and for the lack of need of INR continuous monitoring, with evident advantages in terms of postoperative quality of life. Aspirin therapy in fact completely responds to postoperative expectations, because patients' disappointment toward even timelimited anticoagulation therapy is not infrequent after receiving tissue valve implant. However, aspirin administration in some cases carries the risk of ineffective thromboembolic protection due to aspirin resistance; nevertheless, biochemical tests to disclose this treacherous eventuality are currently available. ${ }^{25}$

The study has some limitations. In fact, the randomization methods (especially in group 1) might imply some bias, and the TCD evaluation, which was chosen because it is noninvasive, is repeatable, and does not require exposure to $\mathrm{X}$-rays, has some intrinsic limits. Furthermore, more definitive information would require the evaluation of a larger cohort of patients.

Nevertheless, aspirin therapy appears to respond appropriately to both cardiac surgeons' and patients' needs in the early postoperative course after aortic valve replacement with tissue valves, evidencing adequate antithromboembolic efficacy with no added risk for bleeding as well as ease of administration.

\section{References}

1. Heras M, Chesebro JH, Fuster V, et al. High risk of thromboemboli early after bioprosthetic cardiac valve replacement. J Am Coll Cardiol. 1995;25:1111-9.

2. Bonow RO, Carabello B, de Leon AC, et al. ACC/AHA guidelines for the management of patients with valvular heart disease. Executive summary. A report of the American College of Cardiology/American Heart Association Task Force on Practice Guidelines (Committee on Management of Patients with Valvular Heart Disease). J Heart Valve Dis. 1998;7:672-707.

3. Bonow RO, Carabello BA, Chatterjee K, et al. ACC/AHA 2006 guidelines for the management of patients with valvular heart disease: 
a report of the American College of Cardiology/American Heart Association Task Force on Practice Guidelines (writing Committee to Revise the 1998 guidelines for the management of patients with valvular heart disease) developed in collaboration with the Society of Cardiovascular Anesthesiologists endorsed by the Society for Cardiovascular Angiography and Interventions and the Society of Thoracic Surgeons. J Am Coll Cardiol. 2006;48:e1-148.

4. Edmunds LH, Clark RE, Cohn LH, et al. Guidelines for reporting morbidity and mortality after cardiac valvular operations. Ann Thorac Surg. 1996;62:932-5.

5. Stein PD, Alpert JS, Bussey HI, et al. Antithrombotic therapy in patients with mechanical and biological prosthetic heart valves. Chest. 2001;119(1 Suppl):220S-7S.

6. Salem DN, Stein PD, Al-Ahmad A, et al. Antithrombotic therapy in valvular heart disease-native and prosthetic. The seventh ACCP conference on antithrombotic and thrombolytic therapy. Chest. 2004; 126(Suppl):457-82.

7. Agnelli G. Current issues in anticoagulation. Pathophysiol Haemost Thromb. 2005;34(Suppl I):2-9.

8. Nunez L, Aguado MG, Celemin D, et al. Aspirin or coumadin as the drug of choice for valve replacement with porcine bioprosthesis. Ann Thorac Surg. 1982;33:354-8.

9. CTSNet. Anticoagulation therapy after aortic tissue valve replacement: final results. Available from: http://www.ctsnet.org/file/AnticoagulationSurveyFinalResultsSlidesPDF.pdf.

10. European Society of Cardiology. Available from: http://www. escardio.org/knowledge/ehs/survey/Valvular_Hear_Disease.htm.

11. Gherli T, Colli A, Fragnito C, et al. Comparing warfarin with aspirin after biological aortic valve replacement: a prospective study. Circulation. 2004;110:496-500.

12. Sundt TM, Zehr KJ, Dearani JA, et al. Is early anticoagulation with warfarin necessary after bioprosthetic aortic valve replacement? J Thorac Cardiovasc Surg. 2005;129:1024-31.

13. Aramendi JL, Agredo J, Llorente A, et al. Prevention of thromboembolism with ticlopidine shortly after valve repair or replacement with a bioprosthesis. J Heart Valve Dis. 1998;7:610-4.
14. di Marco F, Meneghetti G, Gerosa G. Early anticoagulation after aortic valve replacement with bioprostheses: time to abandon it? $J$ Thorac Cardiovasc Surg. 2005;130:1482-3.

15. Razumovsky AY, Gugino LD, Owen JH. Advanced neurologic monitoring for cardiac surgery. Curr Cardiol Rep. 2006;8:17-22.

16. Barbut D, Yao FS, Hager DN, et al. Comparison of transcranial Doppler ultrasonography and transesophageal echocardiography to monitor emboli during coronary artery bypass surgery. Stroke. 1996; 27:87-90.

17. Pugsley W, Klinger L, Paschalis C, et al. The impact of microemboli during cardiopulmonary bypass on neuropsychological functioning. Stroke. 1994;25:1393-9.

18. Deklunder G, Roussel M, Lecroart JL, et al. Microemboli in cerebral circulation and alteration of cognitive abilities in patients with mechanical prosthetic heart valves. Stroke. 1998;29:1821-6.

19. Berger MP, Rams JJ, Davis DA, et al. Asymptomatic microemboli. Neurology. 1993;43:1865.

20. Geiser T, Sturzenegger M, Genewein U, et al. Mechanisms of cerebrovascular events as assessed by procoagulant activity, cerebral microemboli, and platelet microparticles in patients with prosthetic heart valves. Stroke. 1998;29:1770-7.

21. Rams JJ, Davis DA, Lolley DM, et al. Detection of microemboli in patients with artificial heart valves using transcranial Doppler: preliminary observations. J Heart Valve Dis. 1993;2:37-41.

22. Sliwka U, Georgiadis D. Clinical correlations of Doppler microembolic signals in patients with prosthetic cardiac valves: analysis of 580 cases. Stroke. 1998:29:140-3.

23. Eicke BM, Barth V, Kukowski B, et al. Cardiac microembolism: prevalence and clinical outcome. J Neurol Sci. 1996;136:143-7.

24. di Marco F, Giordan M, Gerosa G. Early anti-thrombotic therapy after aortic valve replacement with tissue valves: when the practice diverges from the guidelines. J Thorac Cardiovasc Surg. 2006;131:1223e1-3

25. Pulcinelli FM, Riondino S. More on aspirin resistance: position paper of the Working Group on Aspirin Resistance. Proposal for a Laboratory Test Guiding Algorithm. J Thromb Haemost. 2006;4:485-7. 